\title{
Relationship between transformational leadership, Innovation, Learning and Growth, and Internal Process: Government Organizations
}

\author{
Nazanin Mansouri \\ HELP University \\ Kuala Lumpur, Malaysia
}

\begin{abstract}
The main purpose of this paper is to justify and discuss the relationship among transformational leadership, innovation, learning and growth, internal process within government organizations. Transformational leadership style consists of five components namely vision, intellectual stimulation, inspirational communication, personal recognition, and supportive leadership. Besides, innovation, learning and growth, and internal process are considered as three main perspectives of organization's performance.
\end{abstract}

Keywords: Transformational leadership, Government organizations, Innovation, Learning and Growth, Internal process.

\section{INTRODUCTION}

The government organizations in any country can be considered as the most important sources in different countries for citizen satisfaction and economic growth (Kim, 2005; Trottier et al., 2008; Cho and Park, 2012). In this regard there are a lot of policy makings on improving the performance of these organizations.

The government organizations always attempt to improve their performance. The reason is that this country is dependent to these types of organizations for attracting foreign investors, tourists and also increasing the economic activities (AlKhouri, 2012). The previous studies on the role of human resource management demonstrated that enhancing human resource and investing on it is one of the influential factors on organizational performance. For example Huselid (1995) are among those scholars that emphasized on this aspect. Moreover, RBV or resource based review support this relationship.

One of the important factors which can impact the organizational performance is leadership style. The conducted researches by (Dvir et al., 2002; Pieterse et al., 2010; Wang et al., 2011; Grant, 2012; Moynihan et al., 2012) demonstrated that transformational leadership has the capability to impact different dimensions of performance. This can be supported by many different theories such as social exchange theory (Emerson, 1976) and agency theory (Eisenhardt, 1989).

Because of the fact that government organizations are the main focus of this study, may be eliminating the financial performance brings more reliability for studying the performance. By considering that learning and growth, innovation and internal process can be acceptable dimensions for measuring the performance (through utilizing conducted researches by Kaplan and Norton; 2001), it can be concluded that the existed relationships among these three dimensions were not highly focused in previous studies. On the other hand, transformational leadership has different dimensions including inspirational communication, vision, personal recognition, intellectual stimulation and also supportive leadership that studying the impact of each of them separately can be a gap in previous researches.

One of the methods for improving the performance is using the practices and discussions of human resource management. Related to the influential factors on performance, there are still some ambiguities about dimensions of performance and the relationships between them. However, this study aims to justify and show the relationship between transformational leadership style, innovation, learning and growth, and internal process in government organizations.

\section{LITERATURE REVIEW}

\subsection{EMPRICAL Support for the} Transformational Leadership Model

Bycio et al. (1995) used MLQ-1 in order to realize the five factor model that is efficient and effective enough for the gathered data and contains charisma, intellectual stimulation, individualized consideration as well as managed by the exception. However, this study could not provide enough proof in order to support transformational leadership model (Tepper\& Percy, 1994; Bycio et al., 1995). Moreover, there are many contradictions in reported proof about the structure of the model. Particularly, they recognized a positive relationship among leadership factors that can support transformational leadership model (Tejeda, Scandura, \&Pillai, 2001; Carless, 1998; Avolio et al. 1999).

It can be said that a two factor model which shows an active and passive dimension from leadership has been assumed as being efficient. Based on the latent factor correlation, it was demonstrated that transformational leadership scales are strongly interrelated (rs ranged from .83 to .91 ). In addition, the contingent reward scale had relationship with transformational scales positively (rs ranged from .79 to .83 ). This model showed that latent factor's average inter correlation among the scales of transformational leadership was equal to .88 , and the latent factor's average inter correlation of transformational scales and contingent rewards were .81 .

Avolio et al. (1999) introduced so many models for factor structure related to MLQ-5X. The original model could not provide enough data because of the latent factors inter correlation among the variables of transformational leadership and the high levels of latent correlation among transformational factors and contingent reward. It was noted that subscales of MLQ have high degree of correlation and amount of the variance for the explained scales which have been mentioned with a paradigm of high order.

At last, six factor model was developed through reduced items category and was the most appropriate model for the data when it was compared to a series of existed models 
conceptually. However, the latent factors' average inter correlation regarding transformational scales was .94 (rs ranged from .91 to .95), and the average correlation among the transformational scales and contingent reward was .90 (rs ranged from .86 to .93). in addition, Carless (1998) investigated the MLQ-5X and asserted that there is a model which is proper hierarchical regarding data collection that has charisma, individualized consideration as well as intellectual stimulation revealing various aspects of second order structure known as transformational leadership.

According to the above results, the scholars employed a lot of tactics when they studied the transformational leadership. In addition, Carless noted that MLQ-5X cannot test the individual behaviors coming from transformational leadership but instead can assess the single and hierarchical paradigm of the transformational leadership.

According to Schriesheim, Williams and Pillai (1999), they utilized a global measurement for transformational and transactional leadership opposite to studying the individual sub dimensions. The other scholars used a set of items for assessing the transformational leadership for example Tejeda et al., (2001). This approach was remarkably come from empirical results and it was not following a powerful and theoretical rationale for explaining the key factors allocation to the variables. Other experts for instance Fetter, Podsakoff, Moorman and MacKenzie (1990), introduced their own measures of transformational and transactional leadership.

These three mentioned strategies have some benefits and however we can conclude that adopting an approach that is theoretically driven is critical when evaluating the sub dimensions from transformational leadership. So, we should review the theoretical models developed by Bass (1985) as well as understanding 5 sub dimensions relevant to transformational leadership that can show the level's validity in which not relevant concepts will stay not relevant to each other. In addition, the developed theoretical model by Bass can be used in order to get better outcomes.

\subsubsection{Vision}

According to Bass (1985), the most important transformational leadership aspect is the charisma. According to empirical findings which support this definition, the understood Meta analytical results shown that charisma is remarkably linked to mechanism of effectiveness for instance satisfaction from the leaders (Kroeck, Sivasubramaniam and Lowe, 1996). Scholars had a key role in definition of charisma (Beyer, 1999; Barbuto, 1997). Beyer examined the fact that critical components of charisma were dramatically ignored.

Weber (1968) noted that charisma has five dimensions as ideas bringing radical solutions to problems, gifted person, social crisis, a set of followers interested in exceptional individuals who believe that leader has transcendent powers and also the validity of talents and leaders extraordinary gifts along with many repeated achievements.

In general, charisma as mentioned in transformational model, cannot incorporate all of the noted components such as the effect of surrounding environment of leaders and followers, individual connected qualities to charisma and the existed relationship between charismatic leaders and followers along with leader's transcendent powers which have not been yet explored in previous studies. The vision is known as the critical factor of leadership which is incorporated in a charismatic logical framework.

House (1977) noted that vision is an ideal that demonstrates shared values of the stakeholders. Also McClelland (1975) noted that vision results in adapting organizational values and objectives which can motivate individuals to adapt all of behaviors since the behavior itself is attractive while compared to leader attractiveness or charisma.

In this study, vision can be known as the implicit and mental expression of image that can be idealized regarding future and it is formed by organizational values. It is a general theme when there is charisma. According to Weber (1968), a good vision is a basic element that affects charisma. Based on House (1977), the charisma leaders demonstrate behaviors for example ideology articulation that increases goal clarity, task focus and also value congruence. Current study tries to focus on vision. It can contribute for better recognition of broader idealized concept constructs of the charisma presented by Bass.

\subsubsection{Inspirational Communication}

Bass (1985) suggested that charismatic leaders utilize emotional talks and inspirational allures to arouse motivation of employees that leads to self-interest give up for having better good. Later, Bass (1999) asserted that inspirational motivation and charisma are shown when leader a desirable future is being envisioned by leader, and effectively articulates how it should be achieved, he provided an example, set high performance standards and demonstrates confidence and determination in all of the planned tasks. This will suggests that inspirational motivation and vision could possibly be combined as one united construct.

Bass (1985) asserted that those leaders who are charismatic use the inspirational allures and emotional talks to raise the employee motivation for self-interest giving up and having well-being. Even though many scholars have talked about the fact that it is good to make a difference between vision and inspirational motivation (McClelland, 1975; Barbuto,1997), in following discussion a class of theoretical rationale will be suggested in order to create a difference between vision components of charisma and constructs of inspirational leadership:

Downton (1973) mentioned inspirations are action or powers of raisin emotions or the intellect. Also Yuki (1981) stated that inspiration is the extent to which the leader stimulates enthusiasm among task subordinates which they have accomplished and outwardly comments for making up the confidence for subordinates for performing the assignments successfully and get the team goals in the most appropriate way possible.

In addition, Bass (1985) limited employing the inspirational leadership term when a leader employs none intellectual and emotional qualities for impacting the process. He mentioned that inspirational leaders place emotional qualities to impact the process by means of emotional methods and communications.

Oral communication is assumed as the recruiting aspect in existed definitions regarding inspirational leadership. It is generally used as the motivational tool to enhance follower's emotions, so, the result of joining inspirational leadership and oral communication, we can focus on inspirational communication. It is the employment of emotions appeals and statements to increase the followers' emotions.

In this study, it is noted that inspirational communication can be assumed as the paradigm which is explained as a verbal expression from related positive messages to organizations and employees; these statements provide motivation and confidence among organizational parties.

\subsubsection{Supportive Leadership}

These explanations about individualized consideration shifted into discussing about one recognized aspect which is supportive leadership. For instance Avolio and Bass (1995, p. 
202) stated that leader demonstrates higher individualized consideration through showing general and positive support for attempts of the followers.

The element that totally differing transformational leadership from other new leadership theories is known as 'individualized consideration'. Bass (1985) noted that individualized consideration occurs while the leader has some developmental orientation which shows they will work for having more development inside the organization. Additionally, he demonstrated individualized consideration to followers and properly reacts to their specific needs.

Additionally, there are so many experts in transformational leadership field who also focused on supportive leadership. According to Padsakoff et al. (1990) individualized support is known as the leader's behavior that shows they consider followers and their unique needs.

This study focuses on supportive leadership and uses extensive researches that were done for this discussion. House (1996, p, 327) noted a supportive leader shows a behavior for satisfaction of preference from subordinates and requirements for example demonstrating their concern about subordinates welfare and creating friendly and supportive work environment psychologically. The supportive leadership is the key factor if having effective leadership (House, 1971). Hence, we define supportive leadership is the expression of concerns about followers and their individual well- being within working environment.

\subsubsection{Intellectual Stimulation}

The intellectual stimulation is one of the remarkable underdeveloped dimensions of transformational leadership according to Lowe et al. (1996). By the way, this leadership factor has some behavioral patterns that increases the followers interest regarding organizational issues which effectively help to develop their ability to solve the by means of new methods (Bass, 1985).

It was recognized that the effects of intellectual stimulation are clear in enhancing the followers' capability to conceptualize, comprehend and analyze the problems and high quality solutions that they provide for the organization (Bass and Avolio, 1990). This leadership factor was not the subject of extensive researches, by the way, it contains a more comprehend series of behaviors in comparison to the other transformational leadership sub dimensions.

Hence, this study maintained the intellectual stimulation which was adopted by Bass et al (1985). The intellectual stimulation is known as raising awareness and employee's interest about problems and advancing their ability to solve these issues.

\subsubsection{Personal Recognition}

Based on the theoretical proofs it was realized that there is a remarkable relationship among sub dimensions of transformational leadership and transactional leadership in such a way that the transactional leadership contributes to management through contingent reward and exception. The individual recognition as the contingent reward will give the reward to the followers for getting high performance levels. As Bass (1985) mentioned, a praise expression for the well done works, promotion recommendations and payment increases as well as commendations about best attempt are the examples of contingent reward behaviors.

According to empirical evidence in past studies, the contingent rewards significantly and positively are correlated with transformational leadership and shows a similar relationship method for the sub dimensions that are transformation in general (Tepper \& Percy, 1994; Den Hartog, Van Muijen, \&Koopman, 1997).

There exist a lot of reasons that have been proposed for defining these relationships. In addition, Goodwin et al. (2001) noted that contingent reward scale as assessed by MLQ-5X will get the behaviors that are linked to negotiations about rewards for improvement in performance. Additionally, those associated behaviors to reward provision according to performance are also evaluated by the contingent reward scale. These experts asserted that leader's negotiation for allocating rewards to best performances demonstrates a specific transactional leadership type.

However, by means of giving rewards to followers with well performance it is possible to demonstrate a transformational progress because followers and leaders within transformational leadership contexts have a lot of personal investments regarding vision and all of them are developed in order to be effective organizational participants in the best way. Thus, followers think that the performance level consistent to vision of the firm, will be recognized and specified and will be given a reward.

Goodwin et al. (2001) supported the two factor solution for contingent reward by using (CFA) or the confirmatory factor analysis. These experts interpreted their own achievements as providing support for the fact that contingent reward has transactional and transformational processes. This is highly consistent with work systems models which have good performance (Vandenberg, Richardson, \& Eastman, 1999; Becker \& Gerhart, 1996; Arthur, 1994) and can make differentiation among the reward which has role of controlling mechanism and the reward that acts as the system's designed component for increasing the commitment of the employees.

\subsection{Relationship between Innovation,} Learning and Growth, and Internal Process A lot of researches (Dvir et al., 2002; Pieterse et al., 2010; Wang et al., 2011; Grant, 2012; Moynihan et al., 2012) have been conducted about the impact of transformational leadership on organizational performance. These researches emphasize on different dimensions of performance. These dimensions are learning, innovation and internal process. In addition, a lot of researches have been conducted about the relationship between innovation and learning but these are as one way relationships. However, this can be considered as the gap of previous studies. Moreover, the impact of innovation and learning on none financial performance did not receive enough focus from the past studies. According to Kaplan and Norton (2001), in (BSC) balanced score card four different dimensions can be considered for performance including customer, internal process, financial and learning and growth. Through eliminating the financial performance and customer perspective (government organization), may be the internal process can be considered as another important perspective of performance.

\section{PROPOSED FRAMEWORK AND FUTURE STUDY}

Through using the extant studies and also some theories such as social exchange theory and RBV theory this study proposed the below framework (Fig.1). 


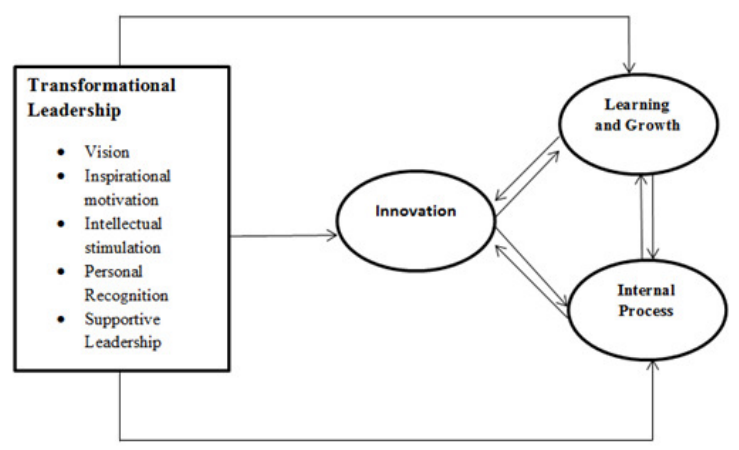

Figure1: Proposed Framework

Through quantitative approach future studies will be capable to examine the relationships between these variables. First, some hypotheses should be developed. Then, the questionnaire should be designed. In order to test the framework, future study needs the middle and top manager experience, so they can be considered as population of study. It should be mentioned that, innovation, learning and growth, and internal process are three dimensions of the performance. However, the interaction between theses dimensions can highlight the importance and priority of each of them. In other words, quantitative approach' results propels future study to develop a new frameworks. In that framework we can see the intervening variables.

\section{REFERENCES}

[1] Al-Khouri, A. M. (2012). e-government Strategies The case of the United Arab Emirates (UAE). European Journal of ePractice, (17), 126-150.

[2] Arthur, J. A. (1994). Effects of human resource systems on manufacturing performance and turnover. Academy of ManagementJournal, 37(3), 670-687.

[3] Avolio, B. J., \& Bass, B. M. (1995). Individual consideration viewed at multiple levels of analysis: A multi-level framework forexamining the influence of transformational leadership. The Leadership Quarterly, 6, 199-218.

[4] Avolio, B. J., Bass, B. M., \& Jung, D. I. (1999). Reexamining the components of transformational and transactional leadership using the Multifactor Leadership Questionnaire. Journal of Occupational and Organizational Psychology, 72,441-462.

[5] Bass, B. (1985). Leadership and performance beyond expectations. New York: The Free Press.

[6] Bass, B. M. (1999). Two decades of research and development in transformational leadership. European Journal of Work andOrganizational Psychology, 8(1), 932.

[7] Bass, B. M., \&Avolio, B. J. (1990).The implications of transactional and transformational leadership for individual, team,organizational development. Research in Organizational Change and Development, 4, 231-272.

[8] Becker, B., \& Gerhart, B. (1996). The impact of human resource management on organizational performance: Progress andprospects. Academy of Management Journal, 39(4), 779-801.
[9] Beyer, J. M. (1999). Taming and promoting charisma to change organizations. The Leadership Quarterly, 10(2), 307-330.

[10] Bycio, P., Hackett, R. D., \& Allen, J. S. (1995).Further assessments of Bass' 1985 conceptualization of transactional andtransformational leadership. Journal of Applied Psychology, 80(4), 468-478.

[11] Carless, S. A. (1998).Assessing the discriminant validity of transformational leadership behaviour as measured by the MLQ.Journal of Occupational and Organizational Psychology, 71, 353-358.

[12] Cho, S. E., \& Park, H. W. (2012). Government organizations' innovative use of the Internet: The case of the Twitter activity of South Korea's Ministry for Food, Agriculture, Forestry and Fisheries. Scientometrics, 90(1), 9-23.

[13] Den Hartog, D. N., Van Muijen, J. J., \&Koopman, P. L. (1997). Transactional versus transformational leadership: An analysisof the MLQ. Journal of Occupational and Organizational Psychology, 70, 19-34.

[14] Dvir, T., Eden, D., Avolio, B. J., \& Shamir, B. (2002). Impact of transformational leadership on follower development and performance: A field experiment.Academy of management journal, 45(4), 735-744.

[15] Downton, J. V. (1973). Rebel leadership: Commitment and charisma in the revolutionary process. New York: The Free Press.

[16] Eisenhardt, K. M. (1989). Agency theory: An assessment and review. Academy of management review, 14(1), 5774.

[17] Emerson, R. M. (1976). Social exchange theory. Annual review of sociology, 335-362.

[18] Goodwin, V. L., Wofford, J. C., \& Whittington, J. L. (2001). A theoretical and empirical extension to the transformationalleadership construct. Journal of Organizational Behavior, 22, 759-774.

[19] Grant, A. M. (2012). Leading with meaning: Beneficiary contact, prosocial impact, and the performance effects of transformational leadership. Academy of Management Journal, 55(2), 458-476.

[20] House, R. J. (1971). A path-goal theory of leader effectiveness. Administrative Science Quarterly, 16, 321-339.

[21] House, R. J. (1977). A 1976 theory of charismatic leadership. In J. G. Hunt, \& L. L. Lawson (Eds.), Leadership: The cuttingedge ( pp. 189-207). Carbondale: Southern Illinois University Press.

[22] House, R. J. (1996). Path-goal theory of leadership: Lessons, legacy, a reformulated theory. The Leadership Quarterly, 7(3),323-353.

[23] Huselid, M. A. (1995). The impact of human resource management practices on turnover, productivity, and corporate financial performance. Academy of management journal, 38(3), 635-672.

[24] Kaplan, R. S., \& Norton, D. P. (2001). Transforming the balanced scorecard from performance measurement to strategic management: Part I. Accounting horizons, 15(1), 87-104.

[25] Kim, S. (2005). Individual-level factors and organizational performance in government organizations. 
International Journal of Science and Engineering Applications

Volume 4 Issue 5,2015, ISSN 2319-7560 (Online)

Journal of public administration research and theory,15(2), 245-261.

[26] Lowe, K. B., Kroeck, K. G., \& Sivasubramaniam, N. (1996). Effectiveness correlates of transformational and transactionalleadership: A meta-analytic review of the MLQ literature. The Leadership Quarterly, 7(3), 385425 .

[27] McClelland, D. C. (1975). Power: The inner experience. New York: Irvington Publishers.

[28] Moynihan, D. P., Pandey, S. K., \& Wright, B. E. (2012). Setting the table: How transformational leadership fosters performance information use. Journal of Public Administration Research and Theory, 22(1), 143-164.

[29] Podsakoff, P. M., MacKenzie, S. B., Moorman, R. H., \& Fetter, R. (1990). Transformational leader behaviors and their effects on followers' trust in leader, satisfaction, and organizational citizenship behaviors. The Leadership Quarterly, 1(2), 107-142.

[30] Pieterse, A. N., Van Knippenberg, D., Schippers, M., \&Stam, D. (2010). Transformational and transactional leadership and innovative behavior: The moderating role of psychological empowerment. Journal of Organizational Behavior, 31(4), 609-623.

[31] Podsakoff, P. M., MacKenzie, S. B., Moorman, R. H., \& Fetter, R. (1990). Transformational leader behaviors and their effectson followers' trust in leader, satisfaction, organizational citizenship behaviors. The Leadership Quarterly, 1 (2), 107-142.
[32] Tejeda, M. J., Scandura, T. A., \&Pillai, R. (2001). The MLQ revisited: Psychometric properties and recommendations. TheLeadership Quarterly, 12, 31-52.

[33] Tepper, B. J., \& Percy, P. M. (1994).Structural validity of the Multifactor Leadership Questionnaire. Educational andPsychological Measurement, 54(3), 734-744.

[34] Trottier, T., Van Wart, M., \& Wang, X. (2008).Examining the nature and significance of leadership in government organizations. Public Administration Review, 68(2), 319-333.

[35] Vandenberg, R. J., Richardson, H. A., \& Eastman, L. A. (1999). The impact of high involvement work processes on organizationaleffectiveness: A second-order latent variable approach. Group and Organization Management, 24(3), 300-339.

[36] Wang, G., Oh, I. S., Courtright, S. H., \& Colbert, A. E. (2011). Transformational leadership and performance across criteria and levels: A meta-analytic review of 25 years of research. Group \& Organization Management, 36(2), 223-270.

[37] Weber, M. (1968).On charisma and institution building. Chicago: University of Chicago Press.

[38] Yuki, G. (1981). Leadership in organisations. Engelwood Cliffs, NJ: Prentice Hall. 